\title{
Evidence for oxidative stress in lens epithelial cells in pseudoexfoliation syndrome
}

\begin{abstract}
Purpose To investigate the oxidative status in lens epithelial cells of patients with pseudoexfoliation (PEX) syndrome. Methods Lens capsule samples obtained during cataract surgery of patients with PEX syndrome and normal age-matched control subjects were examined for changes in the levels of glutathione (GSH), glutathione disulphide (GSSG), protein concentration, and lipid peroxidation. Concentrations of $\mathrm{GSH}$, GSSG, lipid peroxidation, and protein concentration were determined by specific fluorescent assays.

Results This study shows a 2.2- and 2.0-fold decrease in GSH and GSSG levels, respectively, in PEX lens epithelial lens compared with non-PEX lens epithelial cells, as well as a 2.5 -fold increase in lipid peroxidation product malondialdehyde (MDA) levels.

\section{Conclusion The increased MDA and} decreased GSH levels indicate high oxidative stress. On the other hand, GSSG usually increases in cases of high-oxidative stress, but this is not always the case, as it may not always accumulate in cells. Our findings suggest a role for oxidative stress in the pathogenesis and the progression of PEX syndrome.

Eye (2007) 21, 1406-1411; doi:10.1038/sj.eye.6702596 published online 22 September 2006
\end{abstract}

Keywords: pseudoexfoliation syndrome; lens epithelial cells; oxidative stress; glutathione; lipid peroxidation

\section{Introduction}

One of the essential epidemiological demonstrations of the pseudoexfoliation (PEX) syndrome is that it is usually related to age. ${ }^{1}$
SP Gartaganis ${ }^{1}$, NE Patsoukis², DK Nikolopoulos ${ }^{1}$ and CD Georgiou ${ }^{2}$
Ageing is the seemingly inevitable decline in physiologic function that occurs over time. Under certain conditions, such as ageing, alcohol, smoking, or ultraviolet exposure, reactive oxygen species (ROS) production is enhanced and/or the level of antioxidant mechanisms is reduced. The resulting state - which is characterized by a disturbance in the balance between ROS production on the one hand and ROS removal and repair of damaged complex molecules (such as proteins or DNA) on the other - is called oxidative stress. ${ }^{2}$ Oxidative stress is associated with numerous deleterious consequences for the cell (eg, lipid peroxidation or even cell death). Ageing or other oxidative stress-inducing conditions may play a significant role in the development of PEX syndrome. ${ }^{3}$

A disease such as PEX syndrome, which appears to represent a damage to extracellular matrix synthesis, may be related to uncontrolled basement membrane metabolism ${ }^{4-9}$ and the action of free radicals, which are capable of damaging virtually any biomolecules, including proteins, sugars, fatty acids, and nucleic acids. ${ }^{10}$ Studies have also pointed out that free radical damage occurs to long-lived biomolecules such as collagen, elastin, and DNA; mucopolysaccharides; and lipids that make up the membranes of cells and organelles such as mitochondria and lysosomes. ${ }^{11}$

All cells have intracellular antioxidants, such as glutathione (GSH), which are very important for protecting them from oxidative stress at all times. GSH has been found to be decreased in aqueous humour in PEX syndrome, ${ }^{3}$ indicating oxidative stress that can also lead to cell membrane damage.

The goal of this study was to measure the levels of the primary endogenous antioxidant GSH and its oxidized form glutathione disulphide (GSSG), as well as the levels of
8 August 2006

Published online:

22 September 2006 
malondialdehyde (MDA) - a general marker of lipid peroxidation and oxidative stress - in the lens epithelial cells of patients undergoing cataract surgery with PEX syndrome and age-matched control patients without PEX.

\section{Materials and methods}

\section{Study design}

Approval for this study was obtained from the ethical committee of the Regional Hospital of University of Patras (Rio-Patras). Lens capsule samples were obtained from patients with cataract during surgery in the Department of Ophthalmology, Medical School of University of Patras, between January 1, 2003 and March 1,2004 . Written, informed consent was obtained from all patients before participating in the study. Lens capsule sample measurements for this prospective study were performed in the Department of Biology, University of Patras, Greece. All human studies were performed following the guidelines of the Declaration of Helsinki Principle.

\section{Patient selection}

\section{Inclusion criteria}

Ten patients older than 60 years old with PEX syndrome and 10 age-matched control patients were recruited for this study. All patients had senile cataract and were scheduled to undergo routine phacoemulsification for cataract extraction and intraocular lens implantation. All participants underwent a complete ophthalmic examination, including visual acuity testing, applanation tonometry, and slit-lamp examination. The diagnosis of PEX syndrome was made on slit-lamp examination after pupillary dilation, when PEX material deposits were recognized on the pupillary border and/or the anterior capsule. An independent ophthalmologist confirmed these findings by slit-lamp examination. Patients included in this prospective study had intraocular pressure $<20-21 \mathrm{mmHg}$ in both eyes without indications of glaucoma and did not receive any topical medication, except $0.5 \%$ tropicamide and $10 \%$ phenylephrine hydrochloride at the time of surgery.

\section{Exclusion criteria}

We excluded patients with myopia, histories of previous intraocular surgery, laser treatment, glaucoma, uveitis, any posterior segment pathology, or diabetes mellitus or any other systemic disease that might have influenced our measurements. Patients using topical or systemic nonsteroidal anti-inflammatory drugs, or both, or steroids were not included. Subjects with systemic treatment to control arterial hypertension were included in the study.

\section{Patients}

Twenty patients (20 eyes) were enroled, 10 with PEX syndrome (PEX group) and 10 normal controls (non-PEX group). To rule out preoperative differences between patients, the nuclear, cortical, or posterior capsular cataract was graded preoperatively using the Lens Opacities Classification III protocol. ${ }^{12}$ The PEX group consisted of 10 cataract patients with nuclear sclerosis of grade 2 or 3 (four with cortical, two with nuclear, and four with posterior subcapsular cataract) and the non-PEX group of 10 patients with nuclear sclerosis of grade 2 or 3 (three with cortical, four with nuclear, and three with posterior subcapsular cataract).

\section{Human samples}

Lens capsule samples were obtained during cataract surgery and consisted of the anterior capsule (about $6 \mathrm{~mm}$ diameter) that was removed after capsulorhexis procedure. Samples were immediately frozen and stored at $-70^{\circ} \mathrm{C}$ until analysed. Samples were evaluated as soon as possible during 2-3 days of storage.

\section{Reagents}

Thiobarbituric acid (TBA), butyl-hydroxyl toluene (BHT), butyl-hydroxyl anisole (BHA), o-phthalaldehyde (OPT), $N$-ethyl-maleimide, GSH, GSSG, and bovine serum albumin (BSA) were obtained from Sigma Co. (St Louis, $\mathrm{MO}, \mathrm{USA}$ ), trichloroacetic acid (TCA) from Merck (Darmstadt, Germany), MDA bis (dimethyl acetal) from Aldrich (Steinheim, Germany), and butanol-1 from SDS (Peypin, France). All other reagents were of the highest grade.

\section{Sample treatment}

Lens capsule was assayed for GSH/GSSG, lipid peroxidation, and protein concentration after treated as follows: one sample of lens capsule, approximately $4 \times 4 \mathrm{~mm}$, was placed in $90 \mu \mathrm{l}$ homogenization buffer consisting of $10 \mathrm{mM}$ sodium phosphate, $\mathrm{pH} 7.2,1 \mathrm{mM}$ EDTA, and $0.2 \mathrm{mM}$ BHT (in final concentration $0.15 \%$ ethanol). The resulting sample mixture was freezethawed by $5 \times$ immersion in liquid nitrogen and was centrifuged at $15000 \mathrm{~g}$ for $3 \mathrm{~min}$. Thirty microlitres of the resulting supernatant were used for the determination of lipid peroxidation and the proteins of the remaining supernatant $(60 \mu \mathrm{l})$ were precipitated at $25 \%$ TCA (by




ice-water bath for $10 \mathrm{~min}$ and subsequent centrifugation at $15000 \mathrm{~g}$ for $5 \mathrm{~min}$. The resulting supernatant $(60 \mu \mathrm{l})$ was used for the determination of GSH and GSSG, and the protein in the pellet was measured after dissolving it in $50 \mu \mathrm{l}$ of the homogenization buffer by brief sonication (in an ice-water bath), using a sonicator UP-50 H (Dr Hielscher $\mathrm{GmbH}$, Teltow, Germany) set at $350 \mathrm{~W} / \mathrm{cm}^{2}$.

\section{Lipid peroxidation assay}

Lens capsule specimen was assayed for lipid peroxidation by a modified TBA-based method for measuring the aldehydic lipid peroxidation decomposition derivatives (such as MDA), which form fluorescent products after reacting with TBA. ${ }^{13}$ The supernatant $(30 \mu \mathrm{l})$ was brought to $0.15 \mathrm{ml}$ with homogenization buffer, and $0.15 \mathrm{ml}$ TBA reagent $(0.5 \%$ $(\mathrm{w} / \mathrm{v})$ TBA in $20 \%(\mathrm{w} / \mathrm{v})$ TCA and $0.33 \mathrm{~N} \mathrm{HCl})$ was added. A $2 \mu \mathrm{l} 2 \%(\mathrm{w} / \mathrm{v})$ of the lipid antioxidant BHA (made in absolute ethanol) was added to prevent artificial lipid peroxidation during the assay. The mixture was incubated at $100^{\circ} \mathrm{C}$ for $15 \mathrm{~min}$ and brought to room temperature (RT). Then, $0.3 \mathrm{ml}$ butanol- 1 was added and the mixture was mixed by vigorous vortexing, and centrifuged at $15000 \mathrm{~g}$ for $3 \mathrm{~min}$. The fluorescence of the upper butanol layer was measured at excitation $535 \mathrm{~nm}$ and emission $550 \mathrm{~nm}$ against butanol-treated reagent blank $(0.15 \mathrm{ml}$ phosphate buffer plus $0.15 \mathrm{ml}$ TBA reagent). Emission fluorescence units were converted to MDA equivalents from a standard curve using MDA bis (dimethyl acetal) for constructing an MDA standard curve. The standard curve is shown in Figure 1 and is linear in the range of $0.025-2 \mathrm{nM}$. Lipid peroxidation was measured in MDA equivalents concentration expressed in $\mathrm{pmol} / \mathrm{mg}$ protein. Measurements were carried out on a Shimadzu RF-1501 spectrofluorophotometer set at low sensitivity and excitation/emission bandwidth $10 \mathrm{~nm}$.

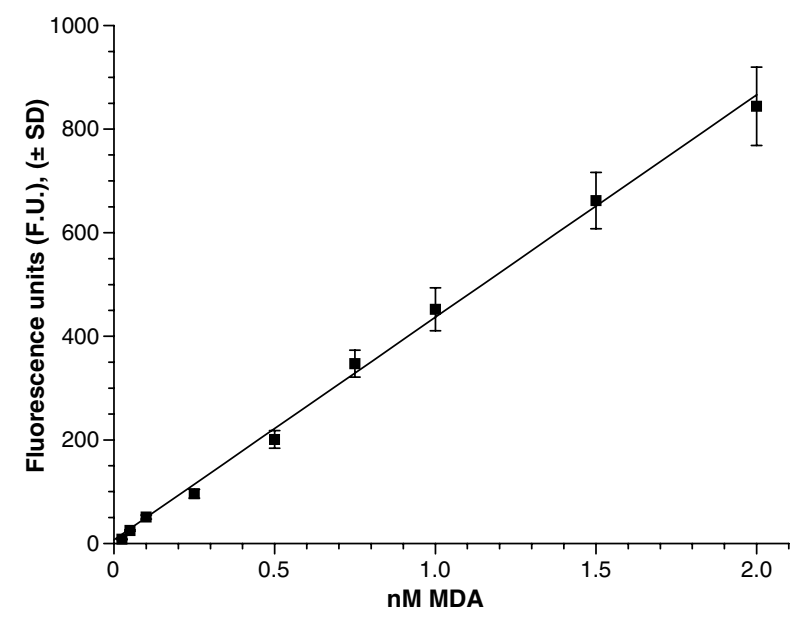

Figure 1 Standard curve of MDA.

\section{GSH/GSSG assays}

GSH and GSSG were assayed by a modification of previous methods based on the reaction of OPT with GSH at pH 8.0 and with GSSG at pH 12.0. In the latter case, any GSH present in mixture with GSSG is first complexed with $\mathrm{N}$-ethyl-maleimide to prevent its interference with GSSG quantification. ${ }^{14,15}$ For GSH determination, 10-20 $\mu \mathrm{l}$ of the resulting supernatant were brought to $50 \mu \mathrm{l}$ with $25 \%$ TCA and were mixed with $0.17 \mathrm{ml} 0.26 \mathrm{M}$ Tris- $\mathrm{HCl}$ (pH 7.8), $0.115 \mathrm{ml} 0.56 \mathrm{~N} \mathrm{NaOH}$ and $0.015 \mathrm{ml} 1 \mathrm{mg} / \mathrm{ml}$ OPT (made in absolute methanol), and the mixture was incubated for $15 \mathrm{~min}$ at RT.

Fluorescence emission of the resulting mixture at $420 \mathrm{~nm}$ was measured after excitation at $320 \mathrm{~nm}$ against a reagent blank (adding $50 \mu \mathrm{l} 25 \%$ TCA in place of the sample) at high spectrofluorometer sensitivity. Emission fluorescence was converted to GSH concentration (in $\mathrm{nmol} / \mathrm{mg}$ protein) from a standard curve of pure GSH (shown in Figure 2), which was linear in the range of $0.1-10 \mu \mathrm{M}$.

For GSSG determination, $10-20 \mu \mathrm{l}$ of the resulting supernatant were brought to $50 \mu \mathrm{l}$ with $25 \%$ TCA, were mixed with $0.02 \mathrm{ml} 40 \mathrm{mM} \mathrm{N}$-ethyl-maleimide and were incubated for $30 \mathrm{~min}$ at RT. Subsequently, $0.15 \mathrm{ml} 0.23 \mathrm{M}$ phosphate buffer ( $\mathrm{pH} 12), 0.105 \mathrm{ml} 0.71 \mathrm{~N} \mathrm{NaOH}$, and $0.025 \mathrm{ml} 1 \mathrm{mg} / \mathrm{ml}$ OPT were added, and the mixture was incubated for $15 \mathrm{~min}$ at RT. Fluorescence emission of the mixture was measured at $420 \mathrm{~nm}$ (using excitation at $320 \mathrm{~nm}$ ) against a reagent blank (adding $50 \mu \mathrm{l} 25 \%$ TCA in place of the sample) at high spectrofluorophotometer sensitivity. Emission fluorescence was converted to GSSG concentration (in $\mathrm{nmol} / \mathrm{mg}$ protein) from a standard curve of pure GSSG (shown in Figure 3), which was linear in the range of $0.1-10 \mu \mathrm{M}$.

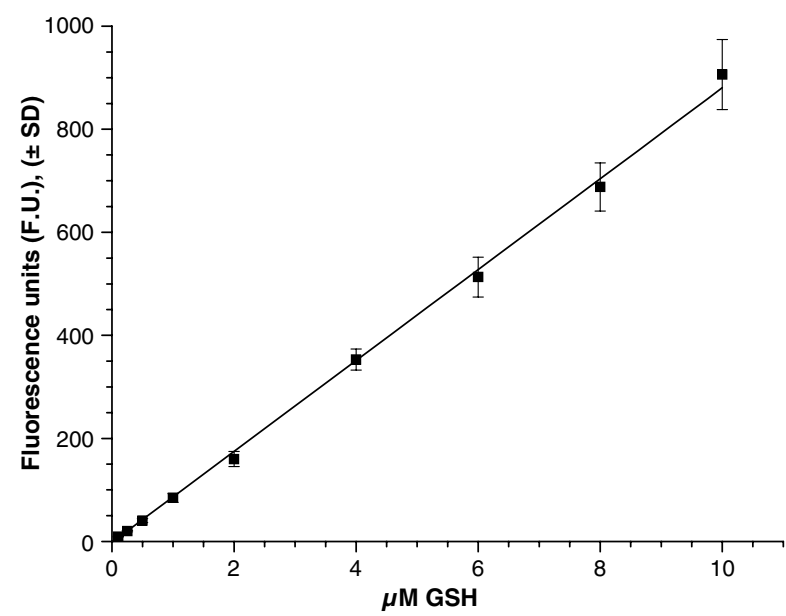

Figure 2 Standard curve of pure GSH. 


\section{Protein assay}

The dissolved protein pellet was assayed by a modification of a CBB-G250-based method. ${ }^{16}$ Ten to twenty microlitres were brought to $81 \mu \mathrm{l}$ with homogenization buffer and $9 \mu \mathrm{l} 12 \mathrm{~N} \mathrm{HCl}$ and $10 \mu \mathrm{l}$ $1 \%(\mathrm{w} / \mathrm{v})$ Triton X-100 were added. The mixture was incubated at $100^{\circ} \mathrm{C}$ for $10 \mathrm{~min}$, was brought to RT, mixed with $0.9 \mathrm{ml} 0.033 \%(\mathrm{w} / \mathrm{v}$ ) CBB-G250 (in $0.5 \mathrm{~N} \mathrm{HCl}$ ), and incubated for $5 \mathrm{~min}$ (minimum time period for colour development). Absorbance was measured at $620 \mathrm{~nm}$ against appropriate blanks (reagent and sample blanks), using a Shimadzu UV-1200 spectrophotometer, and was converted to protein concentration from a BSA $(0-50 \mu \mathrm{g})$ standard curve.

\section{Statistical analysis}

All results are shown as the mean \pm SD. Statistical evaluation of significant differences between the groups of patient was performed, after checking the normal distribution using Kolmogorov-Smirnov method, by means of Student's unpaired $t$-test, unless explicitly stated. Pearson's correlation analysis was used to analyse a potential correlation between age and data sets. Results were considered to be statistically significant when $P<0.05$. Statistical analyses were performed on computer using SPSS statistical software (SPSS for Windows, Version 13.0, SPSS Inc., Chicago, IL, USA).



Figure 3 Standard curve of pure GSSG.

\section{Results}

A total of 20 lens capsule samples were analysed, 10 from the PEX group and 10 from the non-PEX group. The 10 PEX patients enroled in the study had a mean age of $74.9 \pm 8.27$ years and a median age of 74.5 years (range, 60-89 years), with six women and four men enroled. The 10 non-PEX patients enroled had a mean age of $71.6 \pm 7.38$ years and a median age of 70.5 years (range, 62-88 years), with five women and five men enroled. Results of the mean \pm SD measurements can be seen in Table 1. We compared the values in PEX and non-PEX eyes with regard to alterations in the levels of GSH, GSSG, and MDA in the lens capsule. The mean concentration of GSH was found to be $14.32 \pm 5.25 \mathrm{nmol} /$ mg protein $(n=10)$ in the lens capsule of the PEX eyes and $32.06 \pm 6.78 \mathrm{nmol} / \mathrm{mg}$ protein $(n=10)$ in the lens capsule of the non-PEX eyes. In other words, the concentration of GSH was significantly less in the PEX eyes than in non-PEX eyes (Table $1, P=0.000$ ). Nevertheless, the concentration of GSSG was significantly decreased in the PEX group when compared with that in the control group (Table $1, P<0.007$ ).

The mean concentration of GSSG was found to be $48.3 \pm 15.8 \mathrm{nmol} / \mathrm{mg}$ protein $(n=10)$ in the lens capsule of the PEX eyes and $100.4 \pm 46.7 \mathrm{nmol} / \mathrm{mg}$ protein $(n=10)$ in the lens capsule of the non-PEX eyes. Thus, the levels of both GSH and GSSG concentrations showed a 2.2- and 2.0-fold decrease, respectively, in PEX in relation to the non-PEX lens capsules. However, concentrations of MDA were found to be $0.43 \pm 0.18 \mathrm{pmol} / \mathrm{mg}$ in the lens capsules of non-PEX eyes and $1.08 \pm 0.62 \mathrm{pmol} / \mathrm{mg}$ of the PEX eyes (Table $1, P<0.01$ ). It is clear that a 2.5 -fold increase of lipid peroxidation is present in PEX group to the non-PEX group.

\section{Discussion}

PEX syndrome shows strong age-related aggregation in the older population. It must also be noted that ocular PEX syndrome is a bilateral condition and evidence has shown that the risk of bilaterality may be higher by ageing. ${ }^{1}$ It would seem that this high affinity with age reflects the molecular mechanisms of ageing and the effects of various biological and environmental factors

Table 1 Levels of GSH, GSSG, and MDA in the lens epithelial cells of cataract patients with and without PEX syndrome

\begin{tabular}{lrrr}
\hline $\begin{array}{l}\text { Oxidative stress in lens epithelial cells from non-PEX and PEX patients } \\
\text { Oxidative stress indicators }\end{array}$ & Non-PEX $(\mathrm{n}=10)$ & PEX $(\mathrm{n}=10)$ & P-value \\
\hline Lipid peroxidation MDA (pmol/mg) & $0.43 \pm 0.18$ & $1.08 \pm 0.62$ & $<0.01$ \\
GSH (nmol/mg) & $32.06 \pm 6.78$ & $14.32 \pm 5.25$ & 0.000 \\
GSSG (nmol/mg) & $100.4 \pm 46.7$ & $48.3 \pm 15.8$ & $<0.007$ \\
\hline
\end{tabular}


that determine PEX syndrome. One factor that may be suggested as playing a central role in many anterior segment epithelial cells behaviour is the excessive generation of molecules called free radicals, which can result in a state called oxidative stress. It is well established that oxidative stress is implicated in PEX syndrome. ${ }^{3,17}$

Our results provide evidence for an alteration of the antioxidant defense system in lens epithelial cells from patients with PEX syndrome and cataract as compared with age-matched control cataract patients without PEX syndrome. Specifically, levels of GSH and GSSG in PEX lens epithelial cells presented a 2.2- and 2.0-fold decrease, respectively, in relation to the non-PEX lens epithelial cells. Actually, this finding could be important in evaluating the cellular damage of PEX syndrome, as it indicates that the lens epithelial cells are exposed against free radicals, suggesting that localized oxidative stress may contribute to the formation and development of PEX syndrome. Nevertheless, the true pathogenetic origin of this finding is difficult to evaluate, given the fact that GSH decrease may be an outcome of a potential sequence of events during PEX process. In various studies that investigated the role of oxidative stress in the development of cataract, GSH levels are reported to be decreased. $^{14,18}$ The decreased levels of GSH in lens epithelial cells may be attributed to oxidation of GSH to GSSG, yet GSSG levels in lens epithelial cells were found to be decreased too. The fact that GSSG was increased in aqueous humour of PEX patients ${ }^{3}$ may suggest that GSSG does not accumulate intracellularly but is secreted to the aqueous humour. Traditionally, GSH and GSSG are used as indicators of oxidative stress. On the one hand, GSH is considered as the major regulator of the intracellular redox state and participates in redox reactions via the reversible oxidation of its active thiol. ${ }^{19}$ Therefore, decrease of GSH levels is a typical indicator of high oxidative stress. On the other hand, GSSG usually increases in cases of high oxidative stress, but this is not always the case, as it may not always accumulate in cells. This is supported by the fact that GSSG may be secreted from cells, and furthermore, it may be enzymatically converted to GSH (via glutathione reductase (GR)) or it may react with protein thiols to form mixed disulphides (PSSG) via a process called protein-S-thiolation. ${ }^{20}$ Thus, a decrease of GSSG levels may not necessarily be in parallel with a decrease of oxidative stress. Decreased GSH levels have been reported in human ageing lenses and in human cataract lenses, especially in diabetic patients, and it is possible that this may be the case for human lenses with PEX syndrome. GSH decrease has been attributed to the decreased amounts of the GSH biosynthesis pathway enzymes $\gamma$-glutamyl-cysteine synthetase and GSH synthetase. ${ }^{21}$ The failure to regenerate GSH from GSSG via GR and NADPH may be another cause of lowered GSH levels. A decrease in GR activity occurs in human cataract and in most experimental cataract, and possibly in human lenses with PEX syndrome. GR, GSH peroxidase (the enzyme that converts GSH to GSSG using as oxidant organic hydroperoxides), and glucose-6-phosphate dehydrogenase (the enzyme of the pentose pathway that reduces $\mathrm{NADP}^{+}$to $\mathrm{NADPH}$ ) decreased significantly in lenses from diabetic rats. ${ }^{21}$ Additionally, the 2.5-fold increase in MDA levels in PEX patients compared with the control group indicates increased lipid peroxidation in the lens epithelial cells owing to PEX. This observation supports the view that conclusions are straightforward when it comes to MDA levels quantification, as high levels of it are considered as typical indicators of high oxidative stress. ${ }^{17}$

In conclusion, in the present study, we found that the levels of both GSH and GSSG were significantly lower in the lens epithelial cells of patients with PEX syndrome than in that of non-PEX patients. In addition, the lens epithelial cell levels of MDA were significantly elevated. A decrease in GSH and increase in lipid peroxidation suggest increased oxidative stress in PEX lens epithelial cells. The epithelial cells of the central anterior lens capsule analysed are not directly involved in the abnormal matrix metabolism of PEX material synthesis. Nevertheless, our findings may indicate a general biochemical dysfunction of the anterior segment tissues in PEX eyes causing PEX material production.

\section{References}

1 Ritch R, Schlötzer-Schrehardt U. Exfoliation syndrome. Surv Ophthalmol 2001; 45: 265-315.

2 Halliwell B. Antioxidant defense mechanisms: from the beginning to the end. Free Radical Res 1999; 31: 261-272.

3 Gartaganis SP, Georgakopoulos CD, Patsoukis NE, Gotsis SS, Gartaganis VS, Georgiou CD. Glutathione and lipid peroxide changes in pseudoexfoliation syndrome. Curr Eye Res 2005; 30: 647-651.

4 Davanger M, Pedersen OO. Pseudo-exfoliation material on the anterior lens capsule. Demonstration and examination of an interfibrillar ground substance. Acta Ophthalmol (Copenhagen) 1975; 53: 3-18.

5 Harnish JP, Barrach HJ, Hassell JR, Sinha PK. Identification of a basement membrane proteoglycan in exfoliation material. Albrecht Von Graefes Arch Klin Exp Ophthalmol 1981; 215: 273-278.

6 Konstas AG, Marshall GE, Lee WR. Immunogold localization of laminin in normal and exfoliative iris. $\mathrm{Br} J$ Ophthalmol 1990; 74: 450-457.

7 Schlötzer-Schrehardt U, Dofler S, Naumann GO. Immunohistochemical localization of basement membrane components in pseudoexfoliation material of the lens capsule. Curr Eye Res 1992; 11: 343-355. 
8 Fitzsimmons TD, Fagerholm P, Wallin O. Hyaluronan in the exfoliation syndrome. Acta Ophthalmol Scand 1997; 75 257-260.

9 Gartaganis SP, Georgakopoulos CD, Assouti M, Mela EK, Exarchou A, Giannelou I et al. Changes in HNK-1 epitope and collagen type IX in the aqueous humour of patients with pseudoexfoliation syndrome. Curr Eye Res 2004; 28: 5-10.

10 Leibovitz B, Siegel B. Aspects of free radical reactions in biological systems: aging. J Gerontal 1980; 35: 45-56.

11 Harman D. Free radical theory of aging: the free radical diseases. Age 1984; 7: 111-131.

12 Chylalack Jr LT, Wolfe JK, Singer DM, Leske MC, Bullimore MA, Bailey IL et al. The lens opacities classification system III. The longitudinal study of cataract study group. Arch Ophthalmol 1993; 111: 831-836.

13 Zamora R, Alaiz M, Hidalgo JF. Feed-back inhibition of oxidative stress by oxidized lipid/amino acid reaction products. Biochemistry 1997; 36: 15765-15771.

14 Hissin JP, Hilf R. A fluorometric method for determination of oxidized and reduced glutathione in tissues. Anal Biochem 1976; 74: 214-226.
15 Timblin RC, Janssen WMY, Goldberg LJ, Mossman TB. GRP78, HSP72/73, and CJUN stress protein levels in lung epithelial cells exposed to asbestos, cadmium, or $\mathrm{H}_{2} \mathrm{O}_{2}$. Free Radical Biol Med 1998; 24: 632-642.

16 Sedmak JJ, Grossberg ES. A rapid, sensitive, and versatile assay for protein using Coomassie Billiant Blue G250. Anal Biochem 1977; 79: 544-552.

17 Koliakos GG, Konstas AG, Schlotzer-Schrehardt U, Bufidis $\mathrm{T}$, Georgiadis N, Ringvold A. Ascorbic acid concentration is reduced in the aqueous humor of patients with exfoliation syndrome. Am J Ophthalmol 2002; 134: 879-883.

18 Micelli-Ferrari T, Vendemiale G, Grattagliano I, Boscia F, Arnese L, Altomare E et al. Role of lipid peroxidation in the pathogenesis of myopic and senile cataract. $\mathrm{Br} J$ Ophthalmol 1996; 80: 840-843.

19 Patsoukis N, Georgiou D. Determination of the thiol redox state of organisms: new oxidative stress indicators. Anal Bioanal Chem 2004; 378: 1783-1792.

20 Halliwell B, Gutteridge CMJ. Free Radicals in Biology and Medicine. Oxford University Press: Oxford, 1999, pp 936.

21 Ganea E, Harding JJ. Glutathione-related enzymes and the eye. Curr Eye Res 2006; 31: 1-11. 